\title{
Long-term monitoring of rangeland health in the Lower Foothills region of Alberta
}

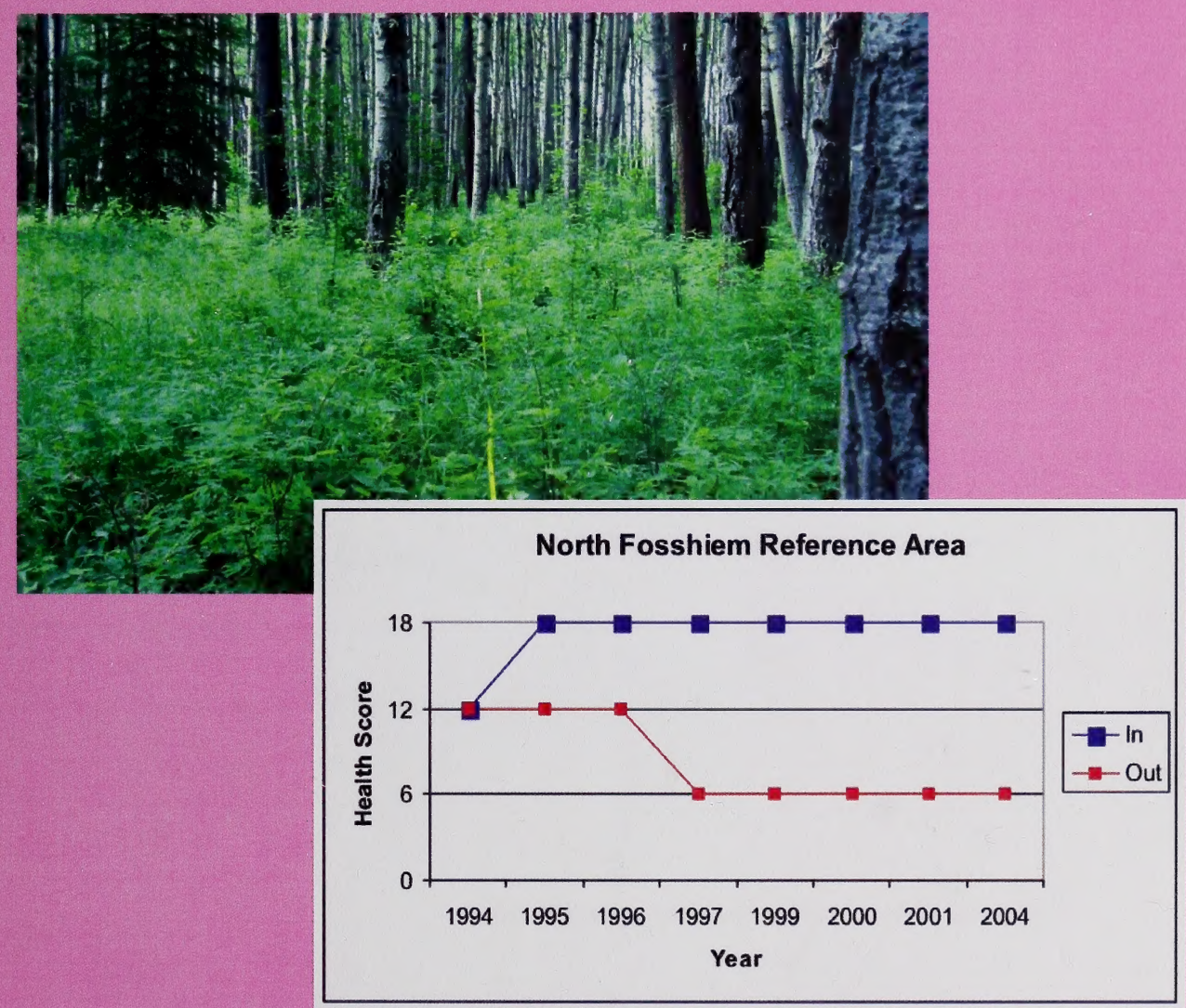

\section{Alberia}

SUSTAINABLE RESOURCE
DEVELOPMENT

Public Lands

\& Forests 



\title{
Long-term monitoring of rangeland health in the Lower Foothills region of Alberta
}

\author{
Prepared by \\ Michael G. Willoughby \\ and \\ Carcey Hincz
}

Edmonton

2005
Alberta Sustainable Resource Development

Public Lands and Forests Division 

Pub No. T/075

ISBN No. 0-7785-4073-1 (Printed edition)

ISBN No. 0-7785-4074-X (On-line edition)

For copies of this report contact:

Michael Willoughby

(780) $422-4598$

E-mail: mike.willoughby@gov.ab.ca

or

Carcey Hincz

(780) $538-8026$

E-mail: carcey.hincz@gov.ab.ca

This report is also available on-line at:

http://www3.gov.ab.ca/srd/land/m_rm_monitoring.html 



\section{TABLE OF CONTENTS}

Introduction

$\begin{array}{ll}\text { Site description } & 1\end{array}$

$\begin{array}{ll}\text { Methods } & 2\end{array}$

Cluster analysis $\quad 2$

Ordination 2

Analysis of rangeland health 4

Results 5

Plant species composition and forage production 5

Plant species diversity and richness

Trends in rangeland health 5

How Integrity and Ecological status relates to rangeland health 11

$\begin{array}{ll}\text { Discussion } & 12\end{array}$

Plant community ecology and forage production $\quad 12$

$\begin{array}{lr}\text { Rangeland health } & 13\end{array}$

Species diversity and ecological status $\quad 13$

Long-term trends $\quad 14$

$\begin{array}{ll}\text { Literature cited } & 14\end{array}$

\section{LIST OF TABLES}

Table 1. Foliar cover (\%) of the dominant species for each Ecological Status score of the forest health short form in the Low-bush cranberry ecological site of the Lower Foothills subregion.

Table 2. The relationship between Ecological Status and the other health questions for the forest health short form in the aspen phase of the Low-bush cranberry ecological site of the Lower Foothills subregion.

\section{LIST OF FIGURES}

Figure 1. Example of plant community groupings and assignment of ecological status scores for each group of the North Fosshiem Reference Area. 
Figure 2. The high cover of shrubs and forbs in this figure is characteristic of an ecological status score of 18 or 12 .

Figure 3. A reduction in the cover of shrubs and tall forbs and an increase in low growing forbs (clover, bunchberry, twinflower, strawberry) as seen in this figure is characteristic of an ecological status score of 6 .

Figure 4. A community that has no shrub cover and the understory is dominated by clover, dandelion and Kentucky bluegrass as seen in this figure is characteristic of an ecological status score of 0 .

Figure 5. Species diversity ( $\left.H^{\prime}\right)$ for each ecological status score 8

Figure 6. Long term change in health of reference areas that had high ecological status when protected and show signs of recovery under no grazing pressure. 9

Figure 7. Long term health of reference areas that had low ecological status when protected which show little sign of recovery in grazed and ungrazed treatments.

Figure 8. Ecological Succession diagram, with ecological status scores and plant community codes (Lane et al. 2000) for the Low-bush cranberry ecological site in the Lower Foothills subregion. 
Digitized by the Internet Archive in 2016

https://archive.org/details/longtermmonitori00will_0 


\begin{abstract}
The Rangeland Reference Area program administered by the Public Lands and Forests Division was established to assess range health and monitor trend on rangelands throughout the province of Alberta. Over 183 fenced and unfenced reference areas have been established throughout the province. These reference areas include permanently marked grazed and ungrazed transects. Species composition data has been recorded on these transects since 1953 when many of the sites were established. Recently, the Alberta Rangeland Health Protocol was developed as a means for assessing the health of Alberta's rangelands (Alberta Rangeland Health Task Group 1999). Rangeland health assessments are utilized to make a rapid determination of the ecological status of rangeland.

Unfortunately, there was not enough historical data from the reference areas to do a detailed rangeland health assessment for each year within a site. Therefore only the ecological integrity and status score of the rangeland health form was used to rate the health of each year within a reference site. The community type within a reference area was assigned an integrity and ecological health status score of $18,12,6$ or 0 to each year within the group. The historic integrity and ecological status scores determined were then compared to recent rangeland health assessments where all the rangeland health ecological functions were assessed and these trends were plotted for each reference area. Over $75 \%$ of the sites that represent the low-bush cranberry ecological site in the Lower Foothills subregion exhibit stable or improving trends in rangeland health.
\end{abstract}





\section{INTRODUCTION}

There are over 6.6 million ha of rangeland in Alberta representing some of the most ecologically diverse areas within the province. These rangelands are important sources of energy (oil and gas), timber, and forage for wildlife and livestock and they are also important for recreation and watershed protection. Alberta Sustainable Resource Development is the Department responsible for the management of public rangeland in Alberta and has a mission "To manage Alberta's natural resources to ensure the benefits Albertans receive from Alberta's public lands and natural resources (forests, rangelands, fish and wildlife) are achieved in a manner that is sustainable, equitable, responsible and in the public interest." The primary goal of public land range management in the province is to deliver an integrated strategy involving range and land management that achieves and maintains the public rangeland under acceptable or greater standard of stewardship based on range and riparian health. To be certain of the achievement of this goal, long-term monitoring of the rangeland resource is required. Monitoring allows us to detect changes in rangeland biological diversity that exceed the range of natural variation. It also allows for pre-emptive actions by providing early warning on changes to rangelands which may be irreversible. Periodic reporting on monitoring activities enables the public to be informed on the status of rangeland diversity in a timely and accessible manner.

This report discusses and evaluates the trends in range health of the Rangeland Reference Areas that represent the low-bush cranberry ecological site within the Lower Foothills Natural Subregion (Lane et al. 2000). There are 4 long-term reference area sites established between 1994 and 2001 that represent the aspen phase of the low-bush cranberry ecological site.

\section{SITE DESCRIPTION}

The low-bush cranberry ecological site accounts for a major component of the primary rangelands in the Lower Foothills subregion of Alberta (Dept. of Environmental Protection 1994). The Lower Foothills is the fifth largest subregion in Alberta (total area of $45,220 \mathrm{~km} 2$ ) and lies west of the Boreal Mixedwood and generally parallel to the Rocky Mountains from northwest of Calgary to the British Columbia border southwest of Grande Prairie (Strong and Leggat 1992). Elevationally this subregion is found below the Upper Foothills and above the Boreal Mixedwood subregions. This subregion has a continental climate with a wide amplitude between summer and winter temperatures. The average annual precipitation is $464 \mathrm{~mm}$, two thirds of which falls during the summer months. Summer temperatures average $12.8^{\circ} \mathrm{C}$ and winter temperatures average $-7.8^{\circ} \mathrm{C}$.

The Lower Foothills subregion is the most arboreally diverse area in Alberta (Strong and Leggat 1992). The mixture of species which can occur is highly dependent upon geographical location and site history. Stands can be dominated by aspen, balsam poplar, lodgepole pine, white spruce, or black spruce. Deciduous-dominated stands are normally found at lower elevations. Secondary succession of these stands is to white spruce. Lodgepole pine-dominated stands develop on rapidly to well drained sites and southerly aspects. Imperfectly drained sites are dominated by lodgepole pine which, with succession, are invaded by white spruce. Black spruce dominates poorly drained depressions throughout the region.

The low-bush cranberry ecological site is regarded as the reference site for the Lower 

Foothills subregion because of the medium nutrient regime and the mesic moisture regime (Beckingham et al. 1996). The plant communities that supply the majority of forage for livestock are generally part of the aspen phase of this ecological site (Beckingham et al. 1996). The primary forage species within these plant communities includes rose, low-bush cranberry, saskatoon, aster, fireweed, tall lungwort, peavine and vetch.

There are four rangeland reference areas that represent various stages of succession of the low-bush cranberry ecological site and aspen ecosite phase. These sites include the North Fosshiem, South Fosshiem, Sandboe and Browning reference areas. Each of these sites is representative of both ungrazed and grazed Aspen/Rose-Low-bush cranberry dominated plant communities.

\section{METHODS}

Reference sites were selected from within dispositions on areas that represented primary range. Sites with a history of overgrazing that were thought to be in poor or declining range health were selected. The reference sites were not located near salt or within $100-\mathrm{ft}$. $(30-\mathrm{m})$ of a fence. The preferred distance from a water source was greater than $1000-\mathrm{ft} .(300-\mathrm{m})$ but less than 1-mi. (1.6-km).

Each reference site consisted of a fenced exclosure and a 100-ft (33-m) transect inside and outside the exclosure. A combination of both ordination (DECORANA) (Gauch 1982) and cluster analysis (SAS) were used to group the inside and outside transects of different years within each reference site. These techniques combined the sites based on the similarity of species composition.

\section{Cluster analysis}

Cluster analysis or classification is the assignment of samples to classes or groups based on the similarity of species. A polythetic agglomerative approach was used to group the samples. This technique assigns each sample to a cluster which has a single measure. It then agglomerates these clusters into a hierarchy of larger and larger clusters until finally a single cluster contains all the samples (Gauch 1982). Cluster analysis was performed in SAS and Euclidean distance was used as the Cluster Distance Measure and Ward's method was used in the Group Linkage Method. The groupings generated in cluster analysis were overlain on the site ordination to determine final groupings.

\section{Ordination}

Ordination was used to find relationships among species, communities and environmental variables. The ordination technique used in the analysis of the monitoring data was DECORANA (Detrended Correspondence Analysis). Groupings were determined by looking for a divergence of the ungrazed and grazed transects for each year into groups with similar species composition which were then called community types (Figure 1). Once final groupings for each site were completed mean species covers were summarized for each year within a group to form a species list. These species lists were assigned to a particular community type 

within a reference area.

\section{North Fosshiem Reference Area}

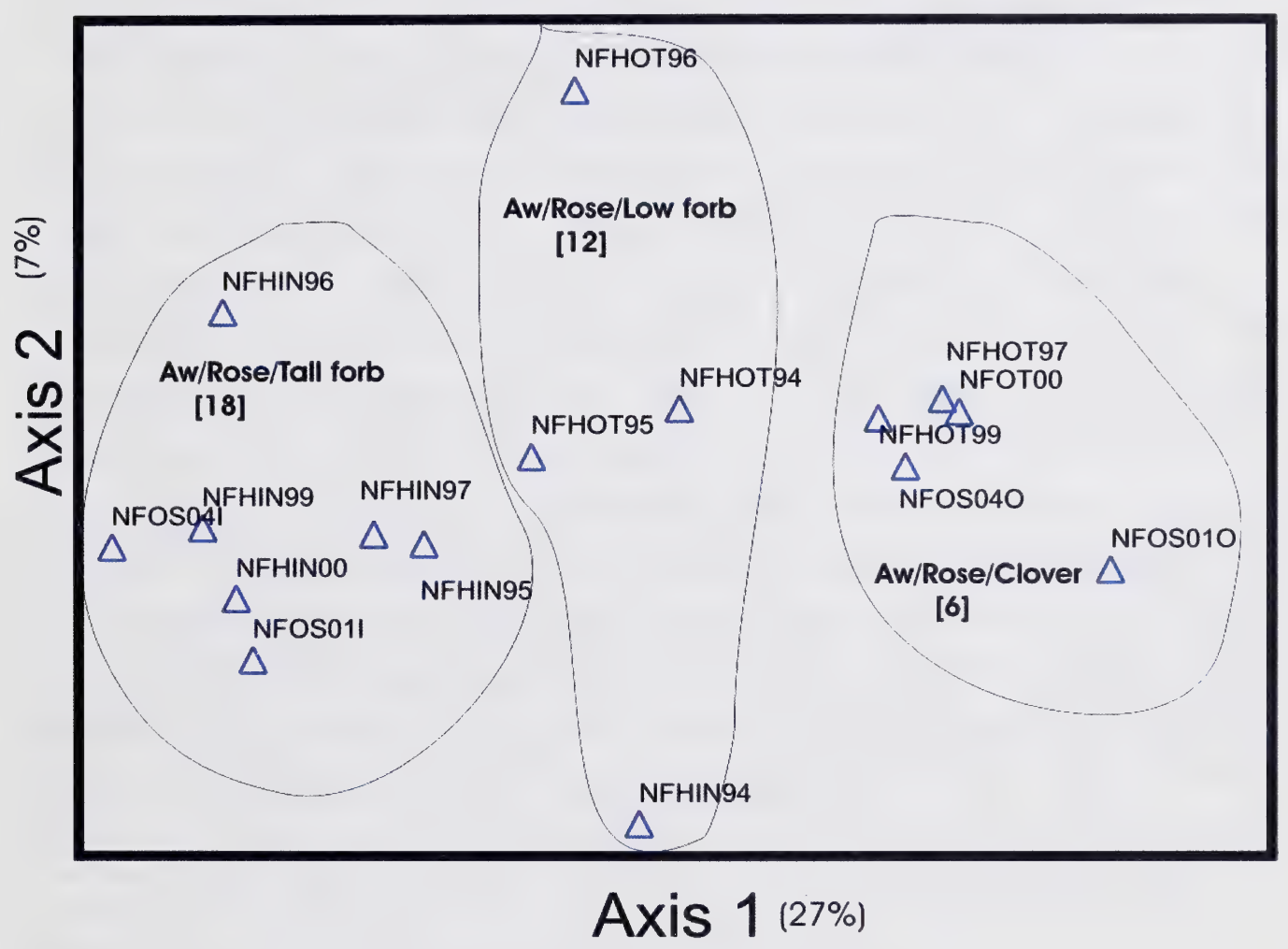

Figure 1. Example of plant community groupings and assignment of ecological status scores $(18,12,6$, or 0$)$ for each group of the North Fosshiem Reference Area. The year "94" represents year of recording, "I or IN" refers to Inside transect, "O or OT" refers to Outside transect. Note the divergence of the inside and outside transects from the original Aw/Rose/Low forb (1994 In and 1994 Out - 1996 Out) dominated community into different plant communities represented by Aw/Rose/Tall forb (1995-2004) on the inside transect and the Aw/Rose/Clover (1997-2004) on the outside transect. 


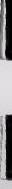




\section{Analysis of rangeland health}

"Rangeland Health" is a term used to describe the ability of rangelands to perform certain key ecological functions. The term health conveys the meaning that all parts of the rangeland system are present and working properly (Adams et al. 2003). The functions of healthy range include: net primary production, maintenance of soil/site stability, capture and beneficial release of water, nutrient and energy cycling and functional diversity of plant species.

The Alberta Rangeland Health Protocol was developed as a means for assessing the health of Alberta's rangelands (Alberta Rangeland Health Task Group 1999). Rangeland health assessments are utilized to make a rapid determination of the ecological status of rangeland. We use range health terminology (healthy, healthy with problems, or unhealthy), to rank the ability of rangeland to perform certain ecological functions. There are five questions within the health assessment that rate the ecological functions of a site. These functions include: net primary production (Structure), maintenance of soil/site stability (Erosion), capture and beneficial release of water (Litter), nutrient and energy cycling (Litter) and plant species functional diversity (Ecological integrity and status and Noxious weeds). For a detailed description on how to assess rangeland health for various plant communities please refer to "Rangeland Health Assessment for Grassland, Forest and Tame Pasture" (Adams et al. 2003).

Unfortunately, there was not enough historical data from the reference areas to do a detailed rangeland health assessment for each year within a site. Therefore only the ecological integrity and status score of the rangeland health form was used to rate the health of each year within a reference site. The community type within a reference area was assigned an integrity and ecological health status score of $18,12,6$ or 0 to each year within the group (Figure 1). An Integrity and ecological status score of [18] indicates a community type that closely resembles the reference plant community for the site and alteration of the plant community due to grazing or other disturbances is minimal. A status score of [12] indicates that compared to the reference plant community, the plant community shows minor alteration due to grazing or other disturbances. A status score of [6] indicates a community that compared to the reference plant community shows moderate alteration due to grazing or other disturbances. A community showing significant alterations due to grazing or other disturbances, compared to the reference plant community was assigned a score of [0] (Adams et al. 2003).

The historic integrity and ecological status scores determined for the reference area plant communities were then compared to recent rangeland health assessments where all the rangeland health ecological functions were assessed. The scores for each of the other ecological functions assessed by the remaining four rangeland health questions were then summarized within each integrity and ecological status score 18,12, 6 and 0 (Table 2). For the rangeland reference area sites, species foliar cover, species richness and species diversity index $\left(H^{\prime}\right)($ Peet 1974) were also summarized for each integrity and ecological status score analyzed using analysis of variance on ranks using NPAR1WAY in SAS, with years within a group as replicates (Figure 5). 



\section{RESULTS}

\section{Plant species composition and forage production}

The species composition for each ecological status score for the four reference areas that represent the aspen phase of the low-bush cranberry ecological site in the Lower Foothills subregion is summarized in Table 1 . In general a community type that was dominated by shrubs (rose, low-bush cranberry, raspberry) and tall forbs (fireweed, tall lungwort, palmate leaved coltsfoot, peavine) was assigned a status score of [18 ], a rose and low forb (strawberry, bunchberry, twinflower) dominated community was assigned a status score of [12]. Sites which had a significantly reduced shrub cover and were dominated by clover and twinflower in the understory were assigned a ecological status score of [6]. A community dominated by Kentucky bluegrass, tall buttercup, dandelion and clover with little shrub cover scored a [0]. Examples of the 18, 12, 6 and 0 ecological status scores are outlined in Figures 2, 3 and 4.

Total forage production declined from a high of over $1000 \mathrm{~kg} / \mathrm{ha}$ for an ecological status score of [18] to a low of $550 \mathrm{~kg} / \mathrm{ha}$ for an ecological status score of [6]. There was no significant difference in forage production between the ecological status scores of [18] and [12] (Table 1). There was no forage production data available from the reference areas for an ecological status score of [0].

\section{Plant species diversity and richness}

When the species diversity $\left(\mathrm{H}^{\prime}\right)$ of these plant communities is plotted against the ecological status score (Figure 5) maximum species diversity corresponded with an ecological status score of [18]. Species diversity tended to be slightly lower under ecological status scores of [12] and [6]. The lowest species diversity was found under an ecological status score of [0] (Table 1). Plant species richness (number of species/plot) tended to follow the same trends as species diversity. The lowest species richness was found with a ecological status score of [6] and $[0]$ (Table 1).

\section{Trends in Rangeland Health}

Long-term trends in rangeland health ecological status of the four reference area sites that had grazed and ungrazed transects are outlined in Figures 6 and 7. Trends in health tend to be different depending on the site's initial ecological status at the time of protection and on the grazing history. Sites which had a higher ecological status [12] when they were first protected generally improved on average within 4 years of being protected from grazing (Figures 6). In contrast sites which had a lower ecological status when they were first protected [6] or [0] (Figure 7) have shown little recovery despite protection periods of over 10 years as in the case of the Browning site. Browning was dominated by Kentucky bluegrass and dandelion with very few native species present when it was first protected which may account for the delay in recovery. In general the ecological status of the grazed transects were all lower than the ungrazed inside transects (Figures 6 and 7). 

Table 1. Foliar cover (\%) of the dominant species for each Ecological Status score of the forest health short form in the Low-bush cranberry ecological site of the Lower Foothills subregion. Health score (Ecological Status)

Species

\section{SHRUBS}

PRICKLY ROSE

(Rosa acicularis)

SNOWBERRY

(Symphoricarpus occidentalis)

BUFFALOBERRY

(Shepherdia canadensis)

LOW-BUSH CRANBERRY

(Viburnum edule)

RASPBERRY

(Rubus ideaus)

FORBS

TALL LUNGWORT

(Mertensia paniculata)

STRAWBERRY

(Fragaria virginiana)

YELLOW PEAVINE

(Lathyrus ochroleucus)

BUNCHBERRY

(Cornus canadensis)

Palmate LEAVED COLTSFOOT

(Petasites palmatus)

DANDELION

(Taraxacum offincinale)

TWINFLOWER

(Linnaea borealis)

Clover

(Trifolium spp.)

TALL BUTTERCUP

(Ranunculus acris)

GRAMINOIDS

MARSH REEDGRASS

(Calamagrostis canadensis)

KENTUCKY BLUEGRASS

(Poa pratensis)

SPECIES DIVERSITY (H')

SPECIES RICHNESS

FORAGE PRODUCTION (KG/HA)

TOtal NUMber Of Plots

\begin{tabular}{llll}
\hline 18 & 12 & 6 & 0
\end{tabular}

$21 \mathrm{~A}$

$19 \mathrm{~A}$

$7 \mathrm{~B}$

0C

$4 \mathrm{~A}$

$4 \mathrm{~A}$

Тв

OB

$4 \mathrm{~A}$

1в

1B

0C

$4 \mathrm{~A}$

$1 \mathrm{~B}$

$1 \mathrm{~B}$

TC

0C

$6 \mathrm{~A}$

0B

Тв

$8 \mathrm{~A}$

2B

2B

3B

7A

$7 \mathrm{~A}$

$5 \mathrm{~A}$

$5 \mathrm{~A}$

$5 \mathrm{~A}$

$5 \mathrm{~A}$

$4 \mathrm{~A}$

$3 \mathrm{~A}$

$4 \mathrm{~A}$

Тв

$6 \mathrm{~A}$

$4 \mathrm{~A}$

0B

TC

2B

TC

OC

TC

4B

$6 A$

OB

$1 \mathrm{c}$

3B

$16 \mathrm{~A}$

$8 \mathrm{~A}$

$11 \mathrm{~A}$

OC

$8 \mathrm{~A}$

$7 \mathrm{~A}$

$18 \mathrm{~A}$

0B

1B

$5 \mathrm{~A}$

$4 \mathrm{~A}$

$1 \mathrm{~B}$

2B

1B

2B

$1 \mathrm{~B}$

3B

$16 \mathrm{~A}$

$2.87 \mathrm{~A}$

$26 \mathrm{~A}$

2.66B

23B

$900 \mathrm{~A}$

$1038 \mathrm{~A}$

11

16

$2.47 \mathrm{C}$
$19 \mathrm{C}$
$554 \mathrm{~B}$
13

$19 \mathrm{C}$

N/A*

6

$2.44 \mathrm{C}$

Note: Means within a row with the same letter indicate no significant difference at the $p=0.05$ level according to a Kruskal-Wallis test.

*Production data from the reference areas not available for this category. 



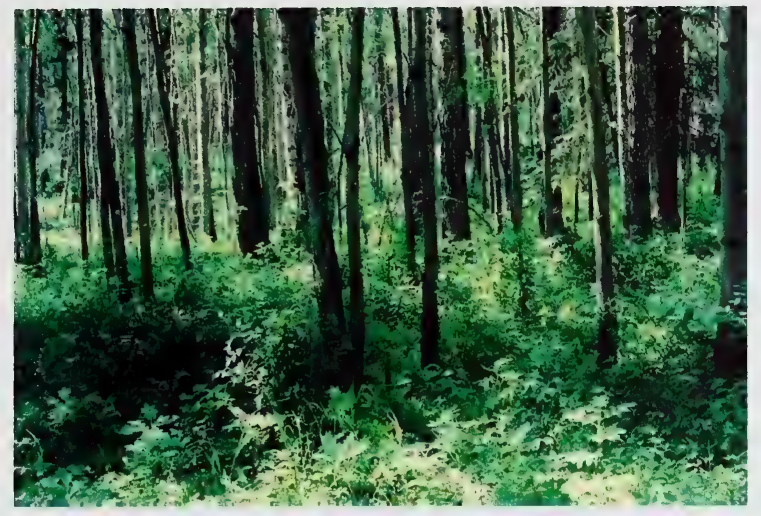

Figure 2. The high cover of shrubs and forbs in this figure is characteristic of an ecological status score of [18] or [12].

Figure 3. A reduction in the cover of shrubs and tall forbs and an increase in low growing forbs (clover, bunchberry, twinflower, strawberry) as seen in this figure is characteristic of an ecological status score of [6].
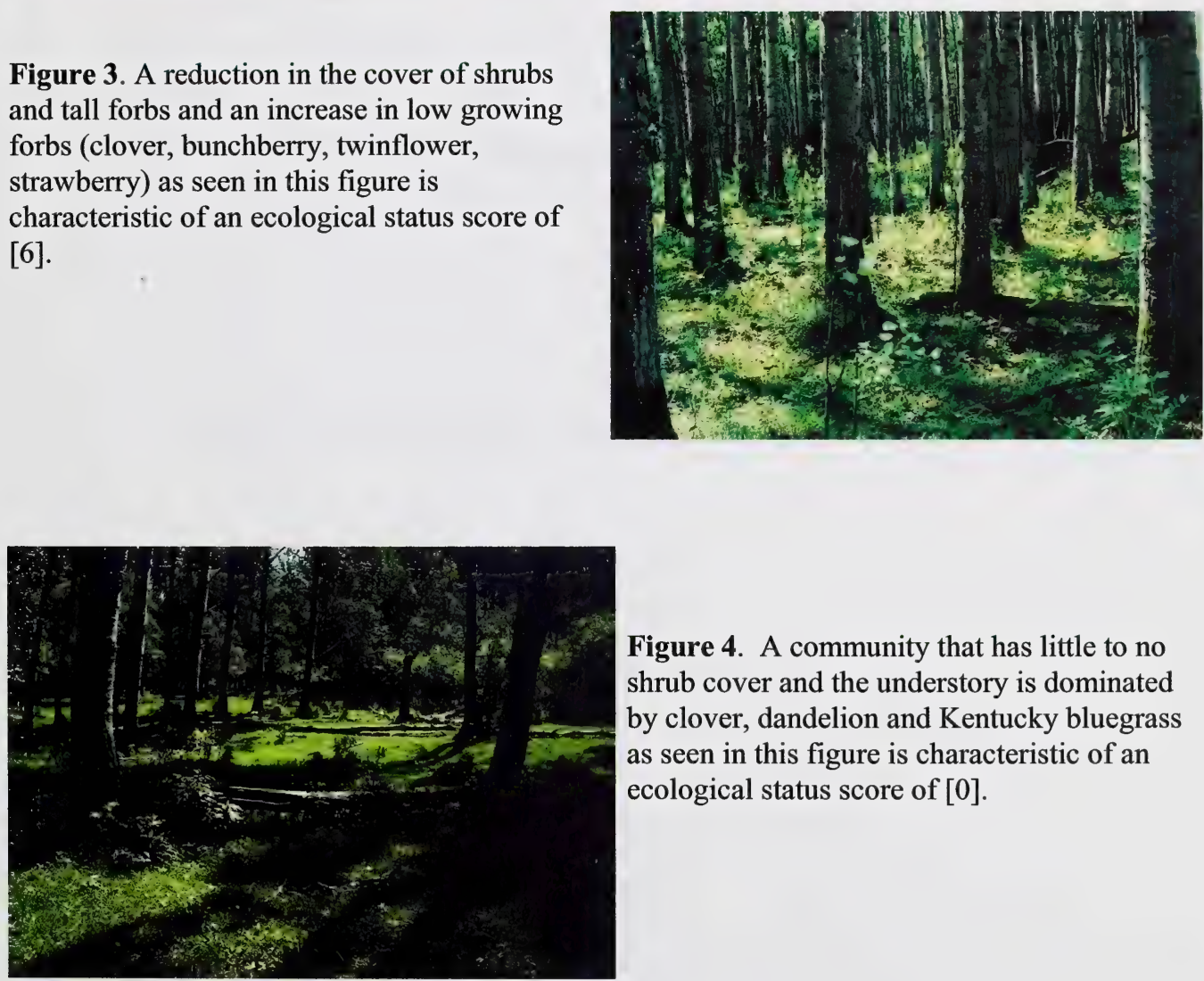

Figure 4. A community that has little to no shrub cover and the understory is dominated by clover, dandelion and Kentucky bluegrass as seen in this figure is characteristic of an ecological status score of [0]. 


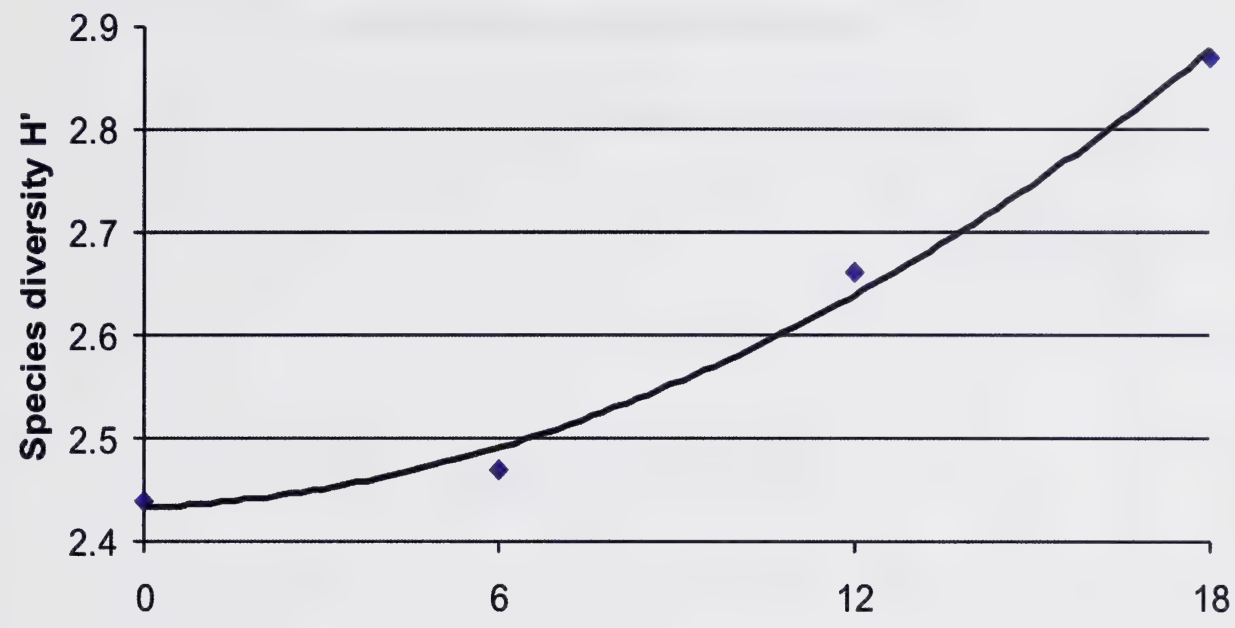

Ecological status score

Figure 5. Species diversity H' for each ecological status score. 


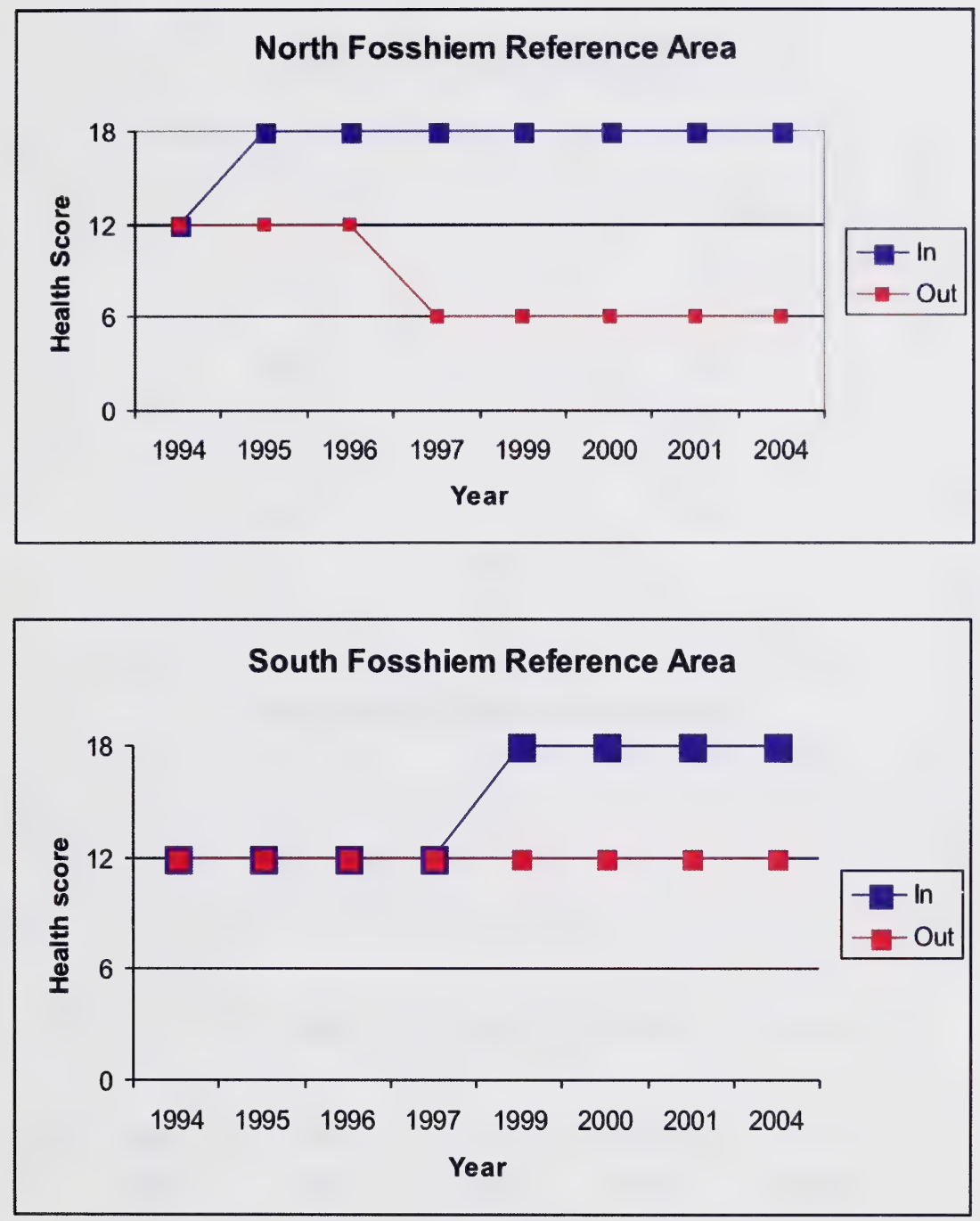

Figure 6. Long term change in health of reference areas that had a higher ecological status when protected and show signs of recovery under no grazing pressure. 


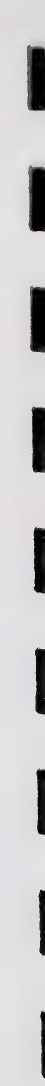




\section{Sandboe Reference Area}

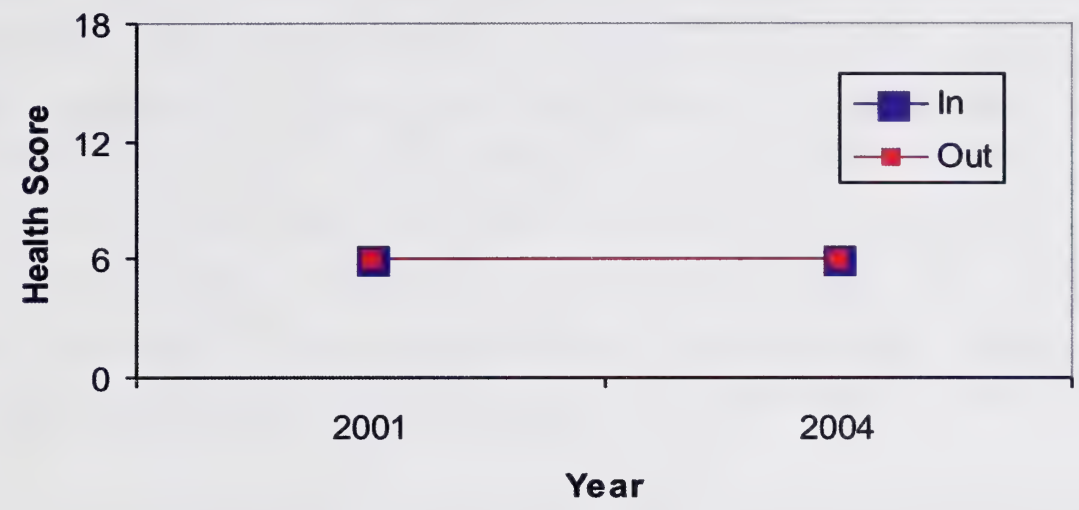

\section{Browning Reference Area}

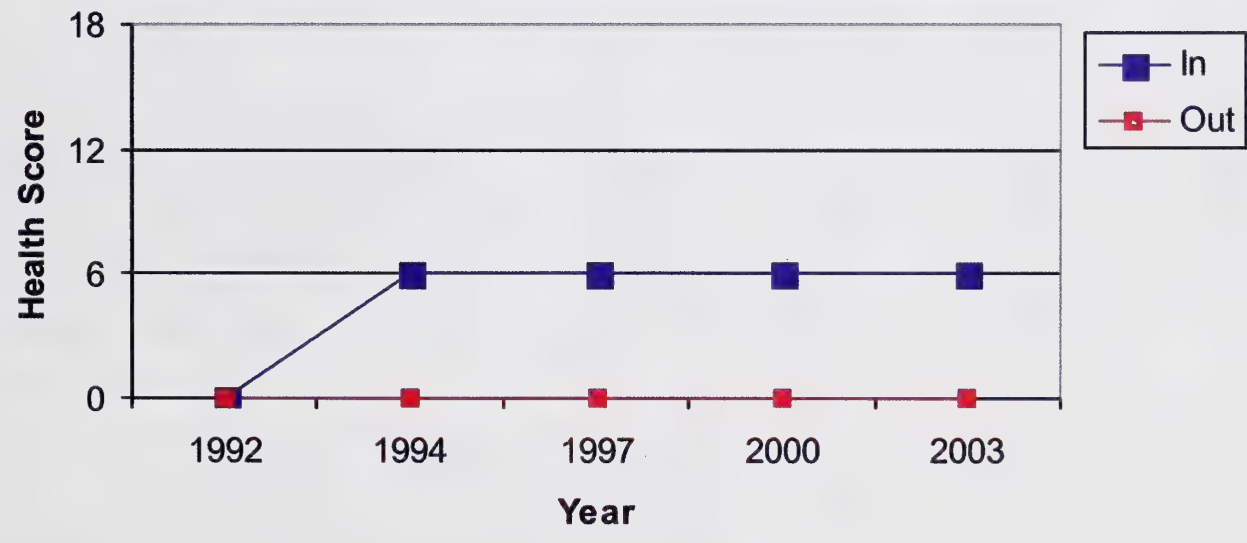

Figure 7. Long term change in health of reference areas that had a lower ecological status when protected and show signs of little to no recovery under no grazing pressure. 

Plant communities with ecological status scores of [18] and [12] generally had good structure with most of the life form layers present in the expected quantities, they were dominated by native species, they had thick LFH layers, they exhibited little bare ground and had very few weeds present in the community (Figure 2, Table 2). The rangeland health score averaged $94 \%$ and $79 \%$ for the ecological status scores of [18] and [12], respectively (Table 2). These scores are within the Healthy category for rangeland health. In contrast an ecological status score of [6] or [0], had poor plant community structure with some major life form layers absent or significantly reduced, they tended to be dominated by non-native species like clover, dandelion and Kentucky bluegrass, they had compacted LFH layers, they exhibited some bare ground and had higher cover of noxious weeds (Figure 3 and 4, Table 2). The rangeland health scores averaged $53 \%$ for an ecological status score of [6] and less than $25 \%$ for an ecological status score of [0] (Table 2). These scores would be rated as healthy with problems and unhealthy, respectively (Adams et al. 2003).

Table 2. The relationship between Ecological Status and the other health questions for the forest health short form in the aspen phase of the Low-bush cranberry ecological site of the Lower Foothills subregion.

Ecological Status Score (mean)

Question (maximum)

\begin{tabular}{llll}
\hline 18 & 12 & 6 & 0
\end{tabular}

1. Integrity and Ecological Status (18)

2. Plant Community Structure (18)

3. Hydrologic Function (LFH)(9)

\section{8}

4. Site Stability (Erosion)(9)

5 . Noxious weeds (6)

Total mean score (100)

Number of plots
6-18(16.3)

$0-9(7.5)$

7-9(8.7)

4-6(5.9)

94

18

12

$12-18(13.5)$

3-9(6.8)

9(9)

6(6)

79

16

6

$6(6)$

3-9(6.8)

$7-9(8)$

4-6(5)

53

4

0

$1-4(3)$

22

5 



\section{DISCUSSION \\ Plant community ecology and forage production}

The successional sequences for the aspen phase of the low-bush cranberry ecological site under grazing pressure are outlined in Figure 8. Protection from grazing will allow shrubs and tall forbs to increase in cover, to form the Aspen/Rose-Low bush cranberry/Tall forb community type. Willoughby (1995) and Lane et al. (2000) found that heavy grazing pressure on deciduous communities in the Lower Foothills subregion caused a decline in the canopy cover of the shrub and forb layers and a corresponding increase in the low forb (strawberry, bunchberry, wintergreen) layer, to form the Aspen/Rose/Low forb and eventually the Aspen/Rose/Clover community types. As heavy grazing continued and became severe, they found that native plant species declined in cover and were replaced by Kentucky bluegrass, dandelion and clover species, to form the Aspen/Kentucky bluegrass/Clover community type. The species composition changes caused by increased grazing pressure severely affects the plant community's ability to create primary production. Willoughby and Lane (2004) found that forage growth and production was $25-40 \%$ lower in the Aspen/Rose/Clover community compared to the Aspen/Rose/Tall forb community and in this study there was over a $54 \%$ drop in forage production between the Aspen/Rose-Low bush cranberry/Tall forb and Aspen/Rose/Clover community types. Maintaining these aspen dominated communities at higher ecological status scores maintains plant species diversity and forage production creating a stable community that will sustain livestock, wildlife and timber production.

\footnotetext{
ND - No disturbance

LD - Light disturbance

MD - Moderate disturbance

HD - Heawy disturbance
}

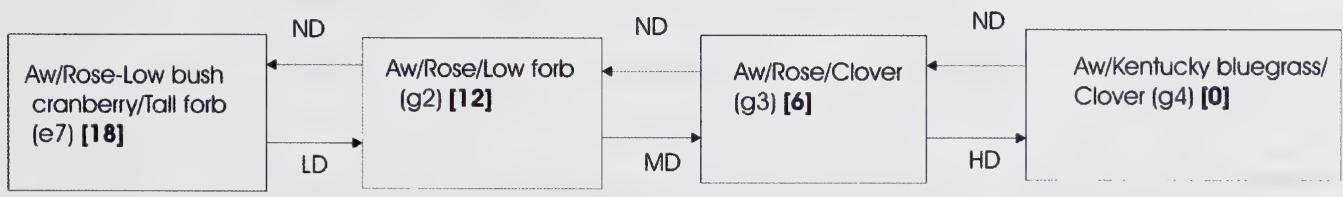

Increasing grazing pressure

Figure 8. Ecological Succession diagram, with ecological status scores and plant community codes (Lane et al. 2000) for the aspen (Aw) phase of the Low-bush cranberry ecological site in the Lower Foothills subregion of Alberta. 



\section{Rangeland health}

New rangeland health protocols have been developed for Alberta rangelands which include measures of plant community integrity and ecological status, site stability, hydrologic function, nutrient cycling and energy flow, plant community structure and noxious weeds (Adams et al. 2003). Ratings are based on a percentage of possible scores for each category. The total possible score is 60 and rangelands are rated as Healthy $(>75 \%)$, Healthy with Problems $(50-75 \%)$ and Unhealthy $(<50 \%)$. These ratings help to determine if a particular ecological site is functioning properly. In the Lower Foothills subregion of Alberta, rangeland health ratings done on sites that are representative of the low-bush cranberry ecological site that scored 'Healthy' generally had ecological status scores of [18] or [12] and were generally represented by a plant community that was dominated by aspen, rose and native forb species. These sites often had high species diversity and higher forage production. In contrast, sites that scored 'Unhealthy' or 'Healthy with Problems' generally had low ecological status scores of [6] or [0] and were represented by plant communities dominated by clover, dandelion, Kentucky bluegrass and tall buttercup. The 'Unhealthy' sites often had the lowest species diversity and lowest forage productivity. It would appear that using ecological status scores from the current rangeland health ratings system to extrapolate trends in range health from long-term monitoring plot data does provide meaningful results. Clearly, the changes in ecological status over time in the presence and absence of disturbance coincides with changes to species composition and rangeland health for each reference area.

\section{Species diversity and Ecological status}

One of the key factors affecting plant species diversity on rangelands is environmental stress. Grime (1973) concluded that species diversity could be plotted as a bell-shaped curve along gradients of environmental stress. Under low environmental stress (grazing, drought, pollution), some species dominate the site by shading lower growing species. As environmental stress increases, the species adapted to low environmental stress lose their competitive advantage and species more resistant to environmental stress increase in abundance. With moderate levels of stress, both species resistant to stress and the species susceptible to stress are able to survive and reproduce resulting in maximum species diversity. Willoughby (1995), found with no grazing stress, native shrubs and forbs dominate the plant community and species diversity and richness is relatively high. When grazing stress increases, the dominant species lose their competitive advantage to the more grazing resistant plant species (i.e. agronomics). Consequently, there is a decline in native plant species and an increase in dandelion, clover, Kentucky bluegrass and weedy plant species, resulting in an overall decline in species diversity and richness.

When the species diversity of the various ecological status scores is plotted along Grime's curve, maximum species diversity in this study occurs with an ecological status score of [18] which was classified as an Aspen/Rose-Low bush cranberry/Tall forb community (Figure 5). These results are somewhat different from the results Willoughby (1995) obtained in the same subregion. Willoughby found that the moderately grazed Aw/Rose/Low forb dominated community had the highest species diversity. This seems to imply that the ungrazed transects in 

the various reference areas which were generally rated with an ecological status of [18] may not be fully recovered from their initial grazing pressure. Indeed the plant communities which had high ecological status scores of [18] and [12] still had significant cover of clover and Kentucky bluegrass (Table 1). In contrast, Willoughby's 1995 study found only trace amounts of both species in the Aspen/Rose/Low forb and Tall forb communities. Future data collection will be necessary to confirm these results.

\section{Long term trends}

When examining long-term trends in the rangeland health of these reference areas, $75 \%$ of the sites exhibit stable or improving trends (Figures 6 and 7). One of the four sites (25\%) that exhibited a downward trend in health (North Fosshiem) reflects a change in management of the entire disposition. The manager of the disposition was experimenting with a new grazing system in the mid 90's and as a result the area around the exclosure has been heavily grazed since 1995.

Clearly, these reference areas have only limited value in reporting the health and trend of all aspen dominated rangelands in the Lower Foothills subregion as they represent only 4 points in the landscape. In order to report the trend and status of all deciduous forest in the Lower Foothills subregion repeated rangeland health ratings on all dispositions over a period of time will have to be recorded.

\section{LITERATURE CITED}

Adams, B.W., G. Ehlert, C. Stone, D. Lawrence, M. Alexander, M. Willoughby, C. Hincz, D. Moisey, and A.Bogen. 2003. Rangeland Health Assessment for Grassland, Forest and Tame Pasture. Alberta Sustainable Resource Development. Public Lands Division. Edmonton. AB. Pub. No. T/044. 104pp.

Alberta Rangeland Health Task Group. 1999. Terms of Reference. Alberta Agriculture Food and Rural Development and Alberta Environment. Edmonton. AB. 12pp.

Beckingham, J., I.G.W. Corns and J.H. Archibald. 1996. Field Guide to ecosites of West-Central Alberta. Special report 9. Canadian Forest Service. Northwest Region. Northern Forestry Centre.

Dept. of Environmental Protection. 1994. Natural Regions of Alberta. Dept. of Environmental Protection. Pub. no. I/531. 18pp.

Gauch, H.G. 1982. Multivariate analysis in community ecology. Cambridge University Press, Cambridge, 298pp.

Grime, J.D. 1973. Control of species diversity in herbaceous vegetation. J. Environ. Manage. 1:151-167. 

Lane, C.T., M.G. Willoughby and M.J. Alexander. 2000. Range plant communities and carrying capacity for the Lower Foothills subregion. $3^{\text {rd }}$ approximation. Alberta Environment. Land and Forest Service. Edmonton. AB. Pub. No. T/532. 232pp.

Peet, R.K. 1974. Species diversity. Ann. Rev. Ecol. and System. 5:245-289.

Strong, W.L and K.R. Leggat. 1992. Ecoregion of Alberta. Alberta Forestry, Lands and Wildlife, Land Information Services Division, Resource Information Branch, Edmonton, Alberta. T/245. $77 \mathrm{pp}$.

Willoughby, M.G. 1995. The effects of grazing on deciduous plant communities in the Boreal Ecoprovince of Alberta. Proc. 5th Int'1 Rangeland Congress. Salt Lake City. Utah. pp 610-611.

Willoughby, M.G. and C.T.P. Lane. 2004. Forage growth and nutrient cycle of Aspen forest communities in Alberta's Lower Foothills subregion. Alberta Sustainable Resource Development. Public Lands and Forest Division. Pub. No. T/064. 11pp. 
(1) 